\title{
APPLICATION OF TWO TECHNIQUES USED FOR MEASURING THE SOIL STRENGTH: A REVIEW
}

\section{Author(s):}

N. Salman ${ }^{1,2}$, P. Kiss ${ }^{3}$

\section{Affiliation:}

${ }^{1}$ Mechanical Engineering Doctoral School, Szent István Campus, MATE University, 2100 Gödöllö, Páter Károly u. 1. , Hungary;

${ }^{2}$ Baquba Technical Institute, Middle Technical University (MTU), Baghdad, Iraq;

3 Institute of Technology, Hungarian University of Agriculture and Life Sciences (MATE), 2100 Gödöllö, Páter Károly u. 1., Hungary

\section{Email address:}

salman.nihal.dawood@phd.uni-szie.hu; kiss.peter@uni-mate.hu

\begin{abstract}
This paper reviews the application of two techniques are used for the measurement of soil strength. The two techniques (cone penetrometer and bevameter) enable measurements to be made in situ. However, the penetrometer is the only equipment that can evaluate soil resistance variation with depth. Neither the cone index nor the gradient that belongs to it concerning the depth is uniquely associated with density or soil cohesion but varies with structural state and moisture content. Moreover, the formation of compaction zones and soil bodies ahead of the cone efficiently alters its geometry, thus the penetration no longer reveals the original characteristics of the soil. Furthermore, the bevameter technique only identifies surface soil properties. Nonetheless, among all the presently available techniques, the bevameter gives the closest imitation of vehicle-terrain interaction.
\end{abstract}

Keywords: cone penetrometer, bevameter, soil measurement techniques, soil properties, plate-sinkage test.

\section{Introduction}

The mechanical characteristics of terrains are usually classified into shearing properties in the tangential direction and bearing in the normal direction (Ding et al., 2014). The proper assessment of the mechanical qualities of a given terrain is primary to forecasting off-road vehicle mobility (e.g., motion resistance, gross traction, and net traction). Mechanical features of soils are measured by numerous techniques, two of which involve the bevameter and the cone penetrometer (Mason et al., 2020). In this work, the employment of the cone penetrometer and the bevameter techniques for estimating surface soils' strength/deformation properties are reviewed.

\section{Cone penetrometers}

Cone penetrometers are part of the simplest and most popularly used instruments for evaluating soil suitability for carrying traffic of ground vehicles. Cone penetrometers supply an indicator for the state of the soil based on cone penetration resistance that relates to shear strength, moisture content, and bearing capacity. They can be utilized to rapidly gather various soil state measurements at different depths in large areas (Goodin et al., 2016)

The cone penetrometer method was developed by the WES (Waterways Experiment Station) of the United States Army Corps of Engineers during the Second World War (Wong, 2010). The aim was to provide reconnaissance personnel and military intelligence with simple field equipment for estimating terrain trafficability and vehicle mobility on a 'go/no go' basis. This cone penetrometer which was developed by WES (Figure 1), has a right circular cone of 30-degree with a base area of $3.23 \mathrm{~cm}^{2}$ and a long shaft of 15.9 $\mathrm{mm}$ in diameter. Also, it contains a proving ring including a handle and a dial gauge are mounted on the shaft's top to show the penetration resistance. Due to the penetration resistance recorded relies on many factors such as shape and size of the cone, surface roughness, and rate of penetration for both convenience 
in describing the results and uniformity in testing, the American Society of Agricultural Engineers has established standards for tests of a soil cone penetrometer (ASAE, 1983; Perumpral, 1987). When penetrometer tests are carried out, the dial indicator is firstly set to zero. After that, dial gauge readings are recorded at each $2.5 \mathrm{~cm}$ added penetration while the penetrometer is pressed into the soil. During the penetration test, it is arduous to sustain a constant penetration rate (almost $1829 \mathrm{~mm} / \mathrm{min}$ ) manually. Therefore, recording type penetrometers with a suitable mechanism for conserving a penetration with a constant rate have been developed to reduce the manpower needed and to avoid a manual operation (Taghavifar et al., 2017). A parameter called the cone index (CI) can be obtained with the penetrometer. It expresses the penetration resistance into the terrain per unit area of the cone base. The index indicates the combined compressive and shear characteristics of the terrain as well as the fiction and adhesion on the interface of cone-terrain (Wong, 2010).
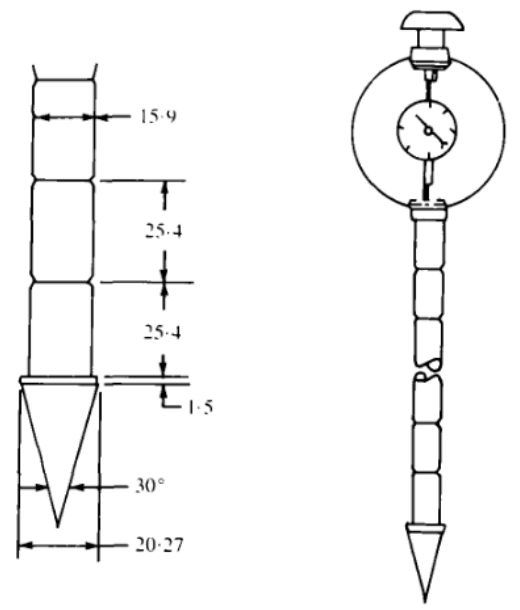

Figure 1. Cone penetrometer (dimensions are in mm) (Okello, 1991)

The measurements of soil strength are influenced by soil water content, clay content (or texture), and bulk density of the soil (Chung et al., 2013). Many studies have employed the equipment to monitor the engineering characteristics of soils and evaluate compaction quality.

Hong et al. (2019) developed a dynamic cone penetrometer (Figure 2) integrated with TDCP (time-domain reflectometry sensors) for estimating the water content of subsurface based on the relative permittivity which compensated by the temperature of the ground and for distinguishing strength via the penetration index. The experimental results were verified and compared to others, as shown in Figure 3.

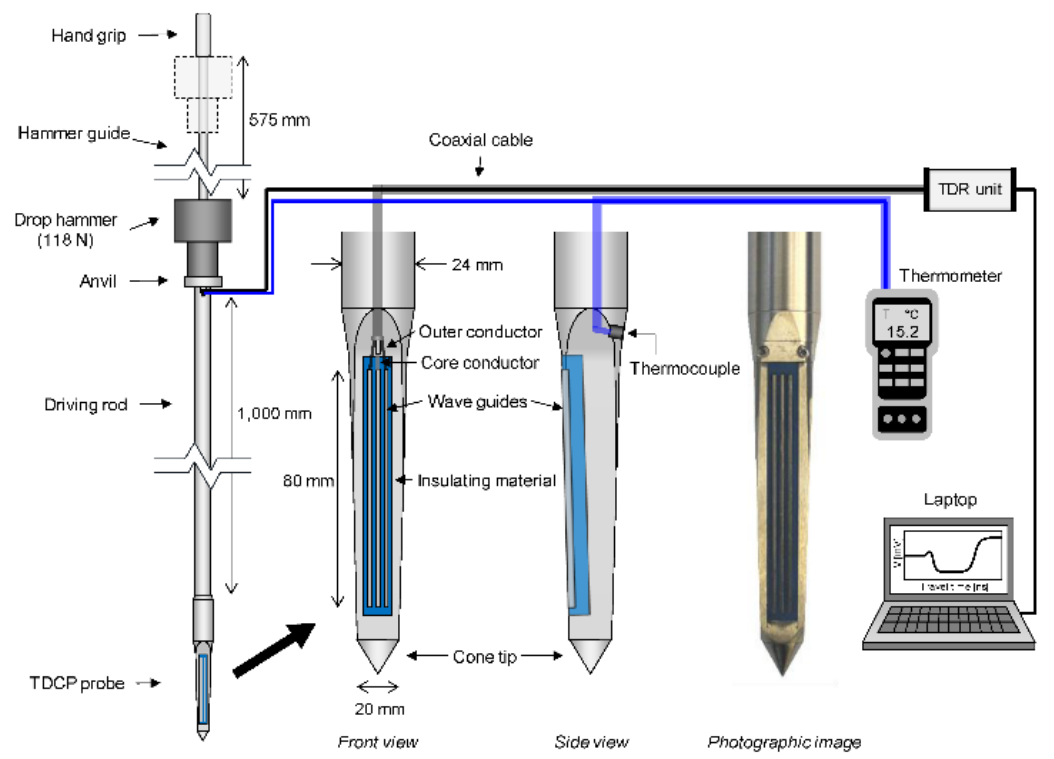

Figure 2. Dynamic cone penetrometer integrated with TDCP (Hong et al., 2019) 


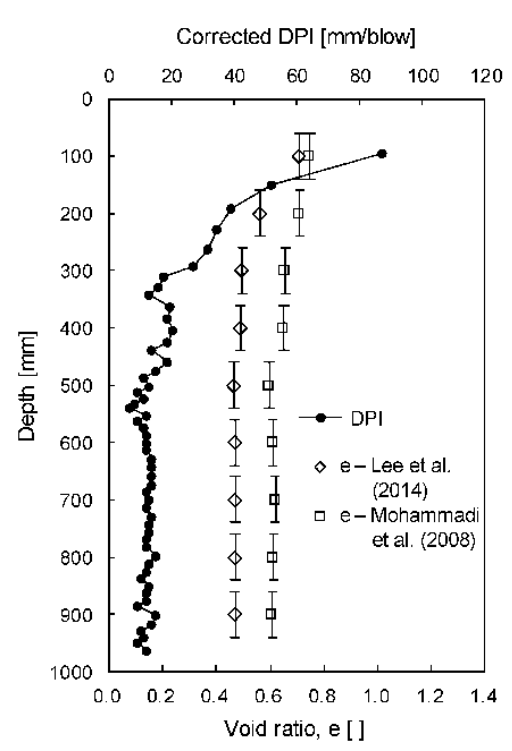

(a)

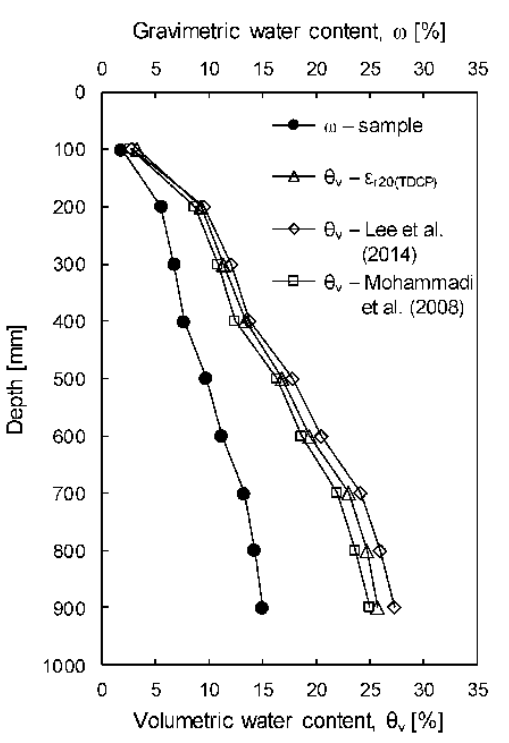

(b)

Figure 3. Verifying the experimental results: (a) Corrected void ratio and dynamic cone penetration index

(DPI); (b) Estimated and evaluated water contents (Hong et al., 2019)

They concluded that the subsurface volumetric water content can be reliably assessed from the test results of the TDCP. Further, the TDCP developed is a portable apparatus for penetration testing that can distinguish ground strength and moisture content with minimal ground disturbance and high mobility.

To determine the distribution of soil density in sandy loam soil deeper layers, Pillinger et al. (2018) employed the cone penetrometer. Their calculated soil density values based on the depth are shown in Figure 4. They found out that the bulk density can immediately be concluded on the field from the outcomes of CI measurements with a modest interference on the soil.

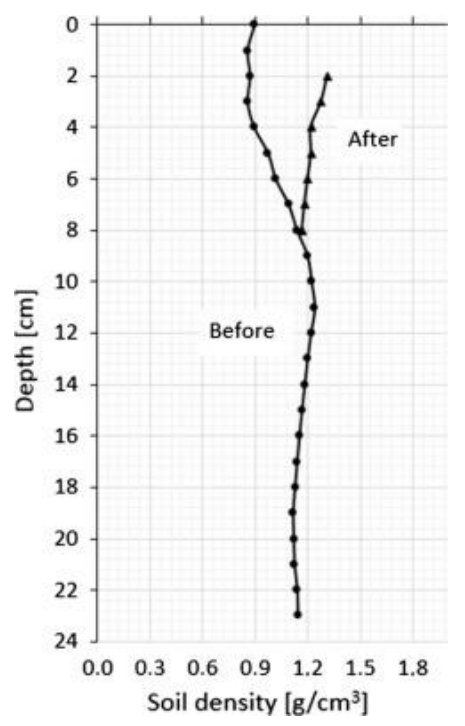

Figure 4. Soil density determined from the cone index (CI) data (Pillinger et al., 2018)

Beckett et al. (2018) used a dynamic cone penetrometer in ripped agricultural soils to detect the compaction after the passage of a heavy tractor, which was ideal for vehicles worked at the test site. Mean penetration resistances as well as their standard deviations at (Test 1) no traffic; (Test 2) agricultural vehicle one pass; and (Test 3) same vehicle five passes are shown in Figure 5. They concluded that dynamic penetrometers are not advised to monitor the compaction of ripped soils for the applied weight of the vehicle. However, the apparatus might be of use when investigating the heavier vehicles' passage.

de Lima et al. (2017) examined the hypothesis that soil matric suction (h) and penetration resistance (PR) do not vary with compactness degree (CD) under various soil textures. Their study explored the agricultural 
field traffic effect on the differences in soil compaction indicators, especially, a) to quantify the immediate impacts of field traffic on the compactness degree, penetration resistance, and matric suction (as shown in Figure 6) and b) to assess the behavior of these variables (on soil type oxisols that have various clay contents) as indicators of compaction after traffic. They concluded that at around field capacity, the clay oxisol is further susceptible to compaction than the sandy clay loam. Texture affected penetration resistance and matric suction for compaction detection. The friction effect diminished with increasing clay, and even with compaction, the variations in penetration resistance were not significant.

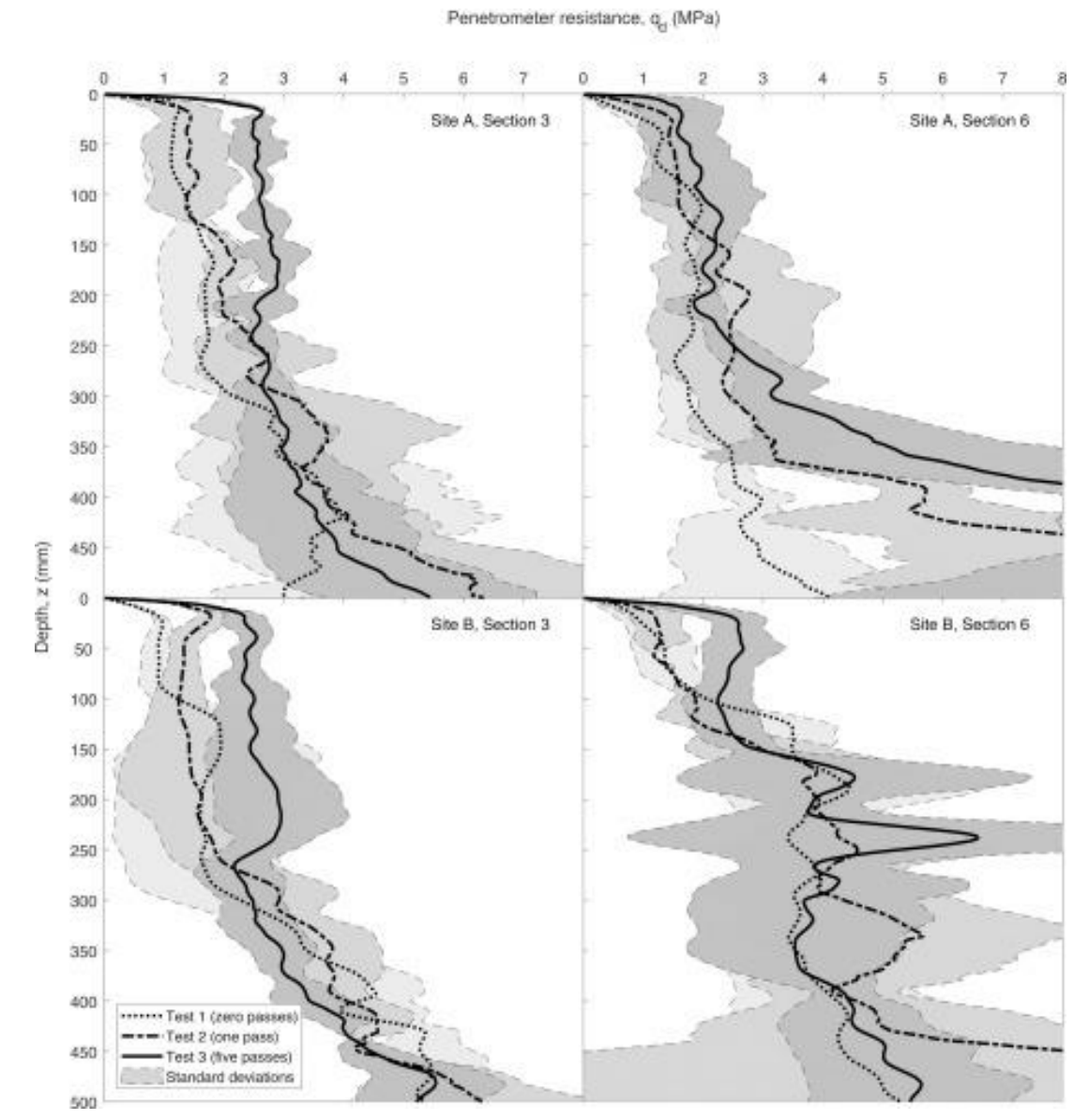

Figure 5. (A) Loamy sand soil [top] and (B) Sandy clay [bottom]: penetration resistance average and standard deviation of tests 1-3 (Beckett et al., 2018)

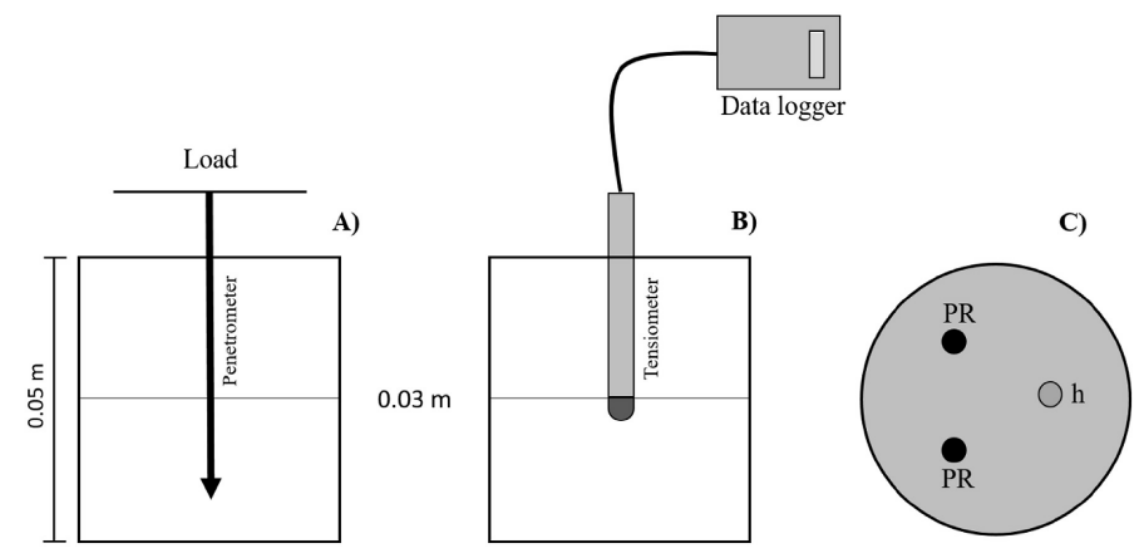

Figure 6. A schematic of the procedure utilized for determining (A) PR and (B) h, both of them were evaluated at a depth of $0.03 \mathrm{~m}$; (C) depicts the soil core surface positions (de Lima et al., 2017) 
Máthé and Kiss (2015) used the cone penetrometer to determine the rolling losses of a towed vehicle.

Lin et al. (2014) Validated four of the existing cone index models using a DSVP (developed dual-sensor penetrometer) (Figure 7). The methodology was to utilize the DSVP in order to simultaneously measure volumetric soil water content $(\theta \mathrm{v})$ and cone index, and subsequently to compare the bulk density coremeasured to that model predicted through the DSVP data. Under the laboratory condition, two soil types (clay soils and silt-loam) were examined. They concluded that two out of four models inspected fit the experimental data. Furthermore, the results intimated that the DSVP coupled with two of the models could be employed as an instrument to predict $\mathrm{Db}$ when $\theta$ and $\mathrm{CI}$ are simultaneously measured.

Miyamoto et al. (2012) employed individual probes for water content $(\theta)$ and penetration resistance (PR) measurements in the same site by employing a TDR (simple time domain reflectometry ) and a conventional cone penetrometer prob. TDR probe mounted on a shaft (Figure 8) was designed for tightly and easily inserting inside the holes that created from the usage of the cone penetrometer.

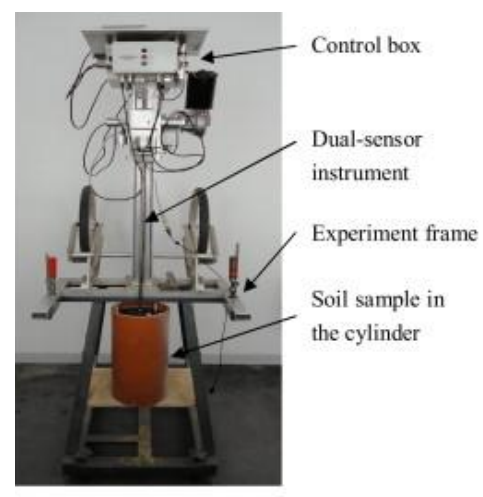

(a)

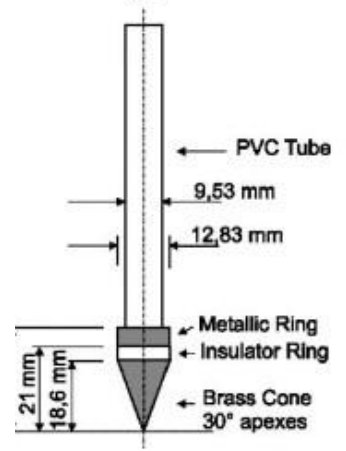

(b)

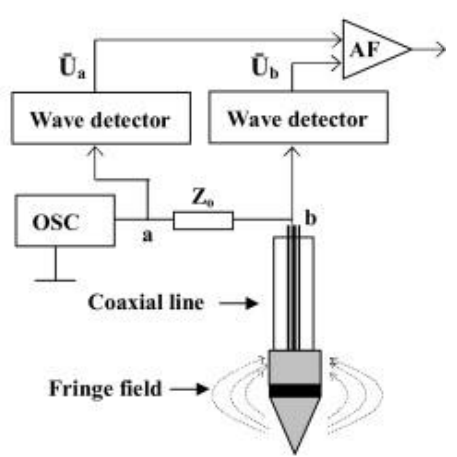

(c)

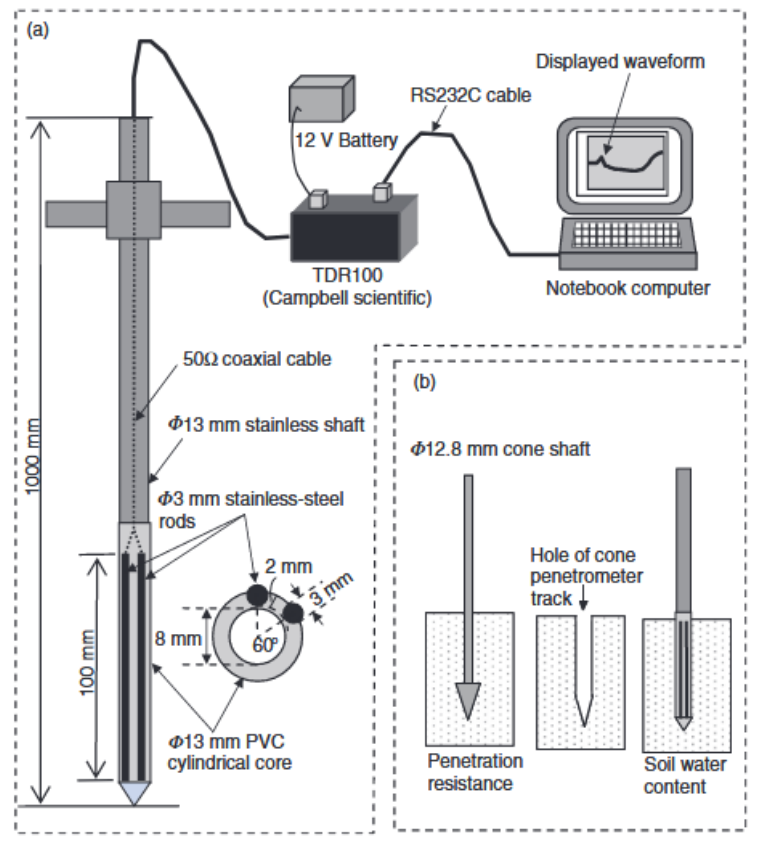

Figure 7. (a) Dual-sensing vertical penetrometer,

(b) Soil water content sensor electric layout, and (c) Combined cone dimension (Lin et al., 2014)

Figure 8. Schematic illustration of (a) TDR probe and measurement system, and (b) TDR measurement utilizing the cone penetrometer hole (Miyamoto et al., 2012)

The results of the PR and $\theta$ measurements shown in Figure 9, the field results illustrate that soil water content and PR have three-dimensional variability, besides a notably various distribution pattern between subsoil and cultivated layers in the field scale. They concluded that their method provides results applicable for the field management of water and soil since it is based on an easy and simple technique for the coincident measurement of PR and soil water content.

Gao et al. (2012) investigated the influence of compaction on cone penetrometer resistance in approximately wet soils at not less than $-30 \mathrm{kPa}$ matric potentials utilizing five soils with diverse organic matter contents and textures. These conditions of soil moisture are characteristic of the matric potentials to which the southeast of England soils drain in winter. They stated that for five soils with different texture, initial soil water content, and organic matter content, the penetrometer resistance is a function of the slope of the compression and the precompression stress characteristic.

To efficiently remove the hardpan, S. Gorucu et al. (2006) developed an algorithm for defining the depth of optimum tillage from the measurements of a soil cone penetrometer. The results of Dothan loamy sand 
soil showed six main patterns of penetrometer profiles. They affirmed that the location and the thickness of the hardpan could be determined from the data of the soil cone penetrometer. They have observed a variation in the thickness and the depth of the hardpan (almost 4 to $25 \mathrm{~cm}$ ) and in the depth of optimum tillage (about 25 to $45 \mathrm{~cm})$.
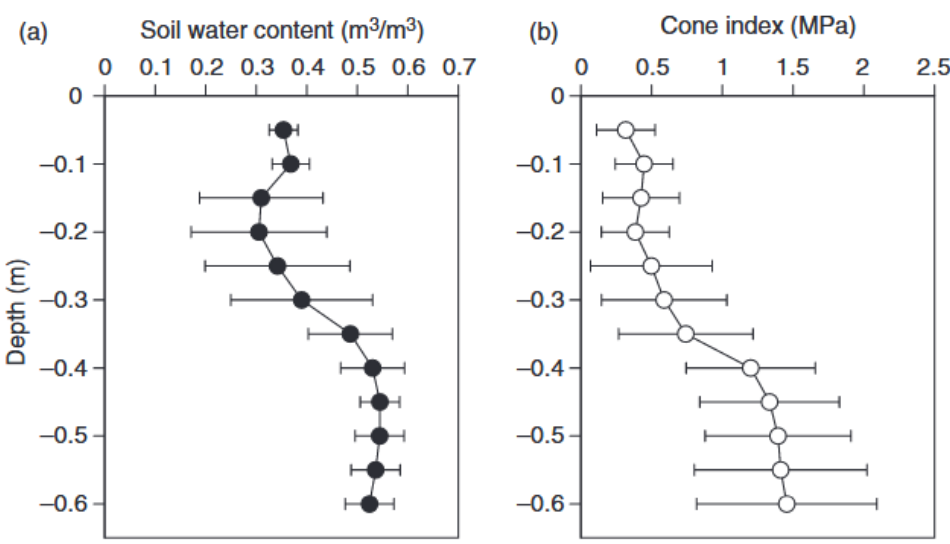

Figure 9. Averaged profiles of (a) Soil water content and (b) Penetration resistance. (Miyamoto et al., 2012)

Herrick et al. (2002) developed a dynamic cone penetrometer (Figure 10) with a durable, low-cost, and reliable alternative to strain gauge-based instruments. They found out that it is particularly suitable for almost all applications that the static penetrometer could be used in a manual operation. Moreover, it is especially useful for implementations in which the conditions of soil are highly unsteady or the operator consistency is questionable. Nevertheless, it is sensitive to variations in soil texture and moisture and could not be utilized as a substitute for soil bulk density direct measurements. Furthermore, the penetrometer could be used to monitor alterations in the condition of the soil in response to management as well as to identify areas where it is required more detailed measurements. Additionally, It could also be utilized to locate potential zones for compaction rapidly within areas and a profile of compaction inside a field.

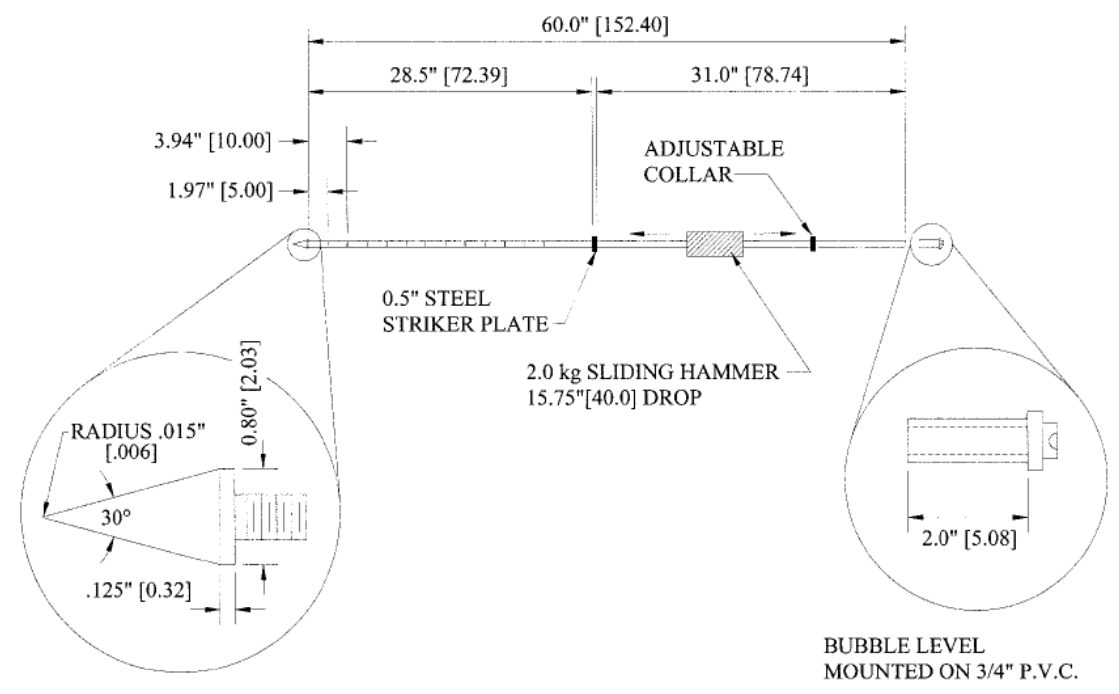

Figure 10. Dynamic cone penetrometer design (the dimensions are in inches [cm]) (Herrick et al., 2002)

Hernanz et al. (2000) utilized the cone penetrometer to construct an empirical model capable to accurately evaluate the bulk density of well-drained loamy soil as well as can be employed to obtain other variables (such as the water accumulated within the soil profile). Figure 11 presents the measured and predicted bulk density profiles during the growing season of the year 1994/95 of the conventional tillage system. They reported that their model has provided good outcomes under field conditions and accurately estimated the accumulated water profiles and soil bulk density profiles. 

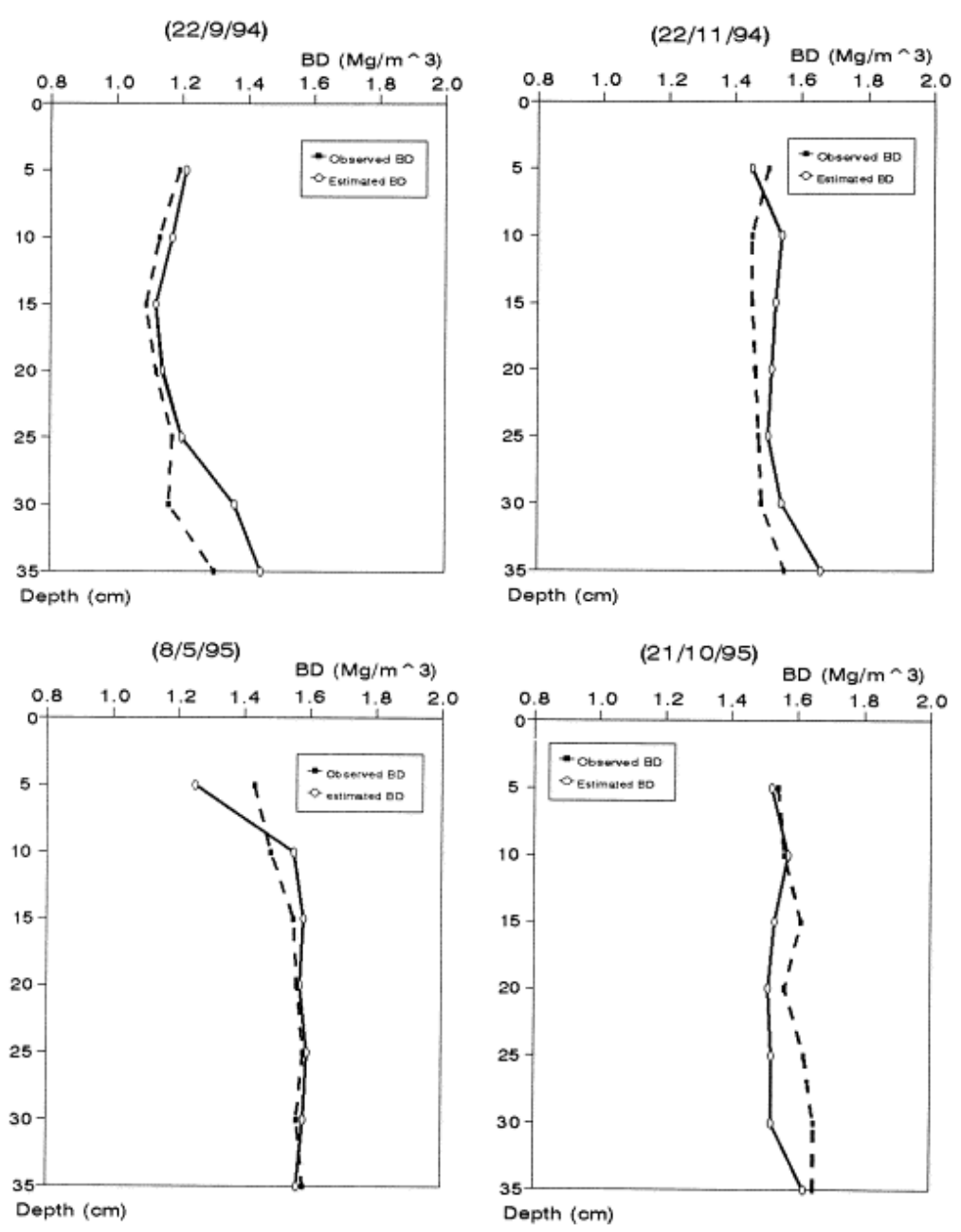

Figure 11. Different soil bulk density profiles measured under the field conditions and investigated with the proposed model (Hernanz et al., 2000)

\section{Bevameter technique}

Bekker (1956) developed the bevameter technique to simulate the forces encountered by a wheel following typical loading conditions through applying standard mechanical loads in soil test beds. Two kinds of tests are usually conducted: the shear test and the plate penetration test. A plate penetration test is useful in estimating a wheel response to a normal load by means of pressing a flat plate on the soil by a piston and then measuring the response by a vertical motion displacement transducer and a load cell. The soil pressuresinkage relationship is measured throughout the penetration test. Through a shear test of bevameter, an annular shear ring under pre-selected normal stress mimics the vehicle running-gear shearing action by rotating over the terrain surface. The corresponding angular displacement and the applied torque are measured during the test (Edwards et al., 2017). Janosi states, "the bevameter is the standard method for scientific and engineering exploration of soils and off-road vehicle design" (Mason et al., 2020). Figure 12 shows the original bevameter which was built at the Newcastle University, upon Tyne, England, and extensively modified at the University of Carleton, Ottawa, Canada (Wong, 2010). Several studies have developed and used the device to measure the terrain properties under loading.

Mähönen et al. (2021) modified a portable bevameter (shown in Figure 13) to estimate the snow's mechanical properties. The aim of the bevameter was to measure the properties of snow which could be utilized to simulate the interaction between soft snow and a snowmobile. Figure 14 demonstrates the result of pressure-sinkage of plate diameters of $200 \mathrm{~mm}$ and $300 \mathrm{~mm}$. They reported that the built bevameter is a tool that could be used for the measurements of the field to estimate snow properties for the simulations of the snowmobile-size vehicle by sensor ranges: Force: 0-2 kN, Torque: 0-200 Nm, and Distance: 0-600 mm, which cover a broad range of typical snowmobiles. Furthermore, the constructed equipment could be utilized to classify different sorts of snow and to recognize hard layers. 


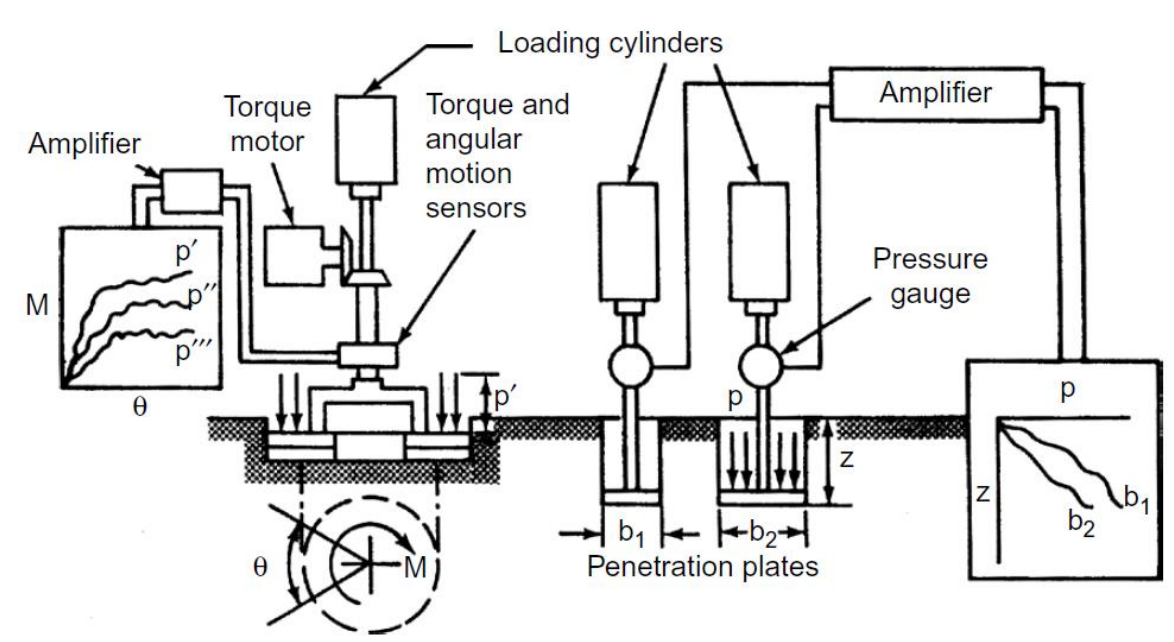

Figure 12. Bevameter schematic diagram (Wong, 2010)
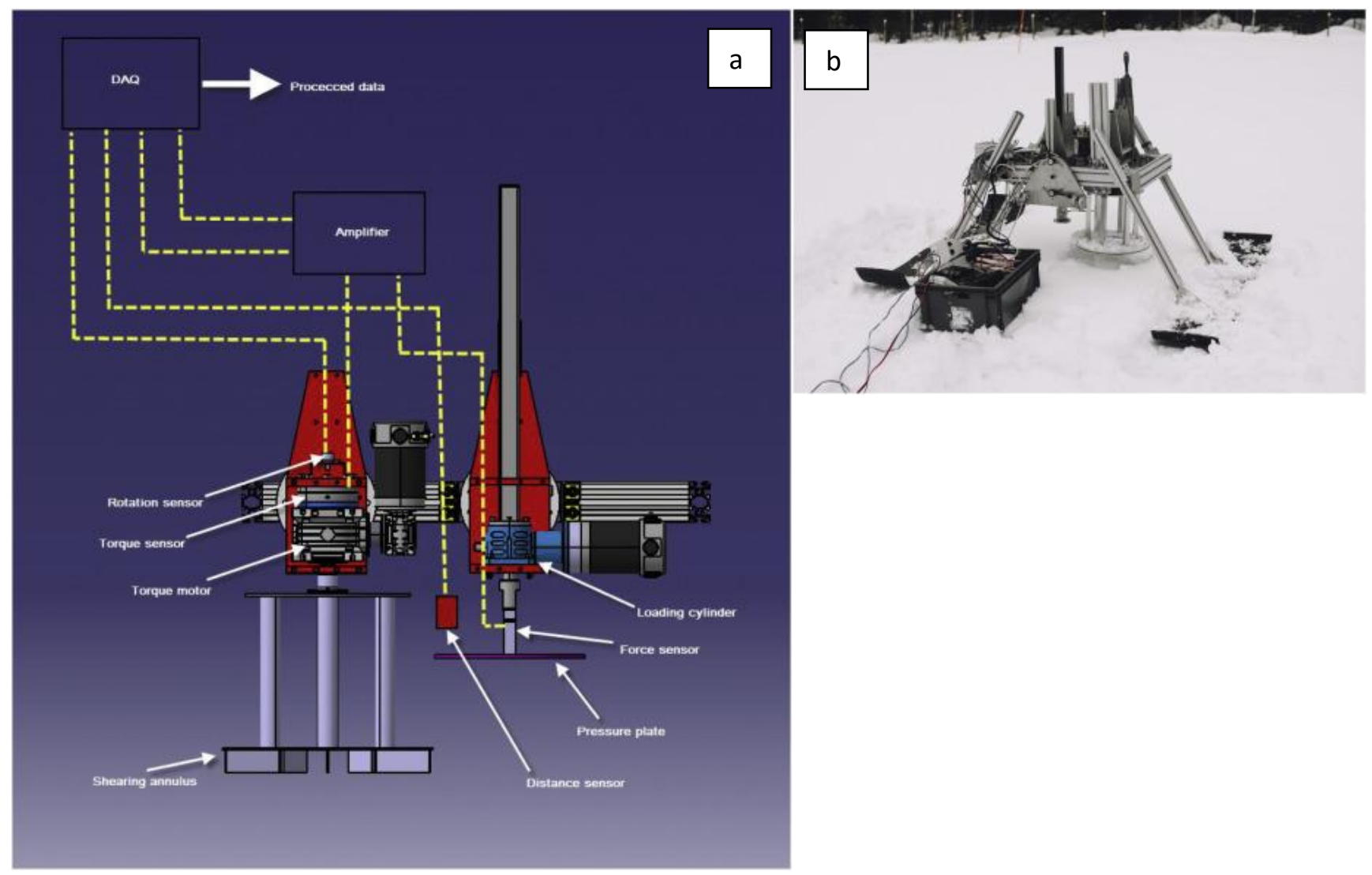

Figure 13. (a) Bevameter schematics. (b) testing of bevameter (Mähönen et al., 2021)

Massah et al. (2010) designed a tractor-mounted bevameter (shown in Figure 15) with various shapes and sizes of plates (rectangular, circular, and oval) and examined it in a loam soil type field. By employing statistical analysis and diagrams produced from collected data, they found out that the sinkage plate shapes had a considerable impact on the soil parameters. Further, the vertical deformation of the soil is influenced by the sinkage plate shape. Moreover, the values of soil parameters are affected by the values of dimension plate and pressure-sinkage. 

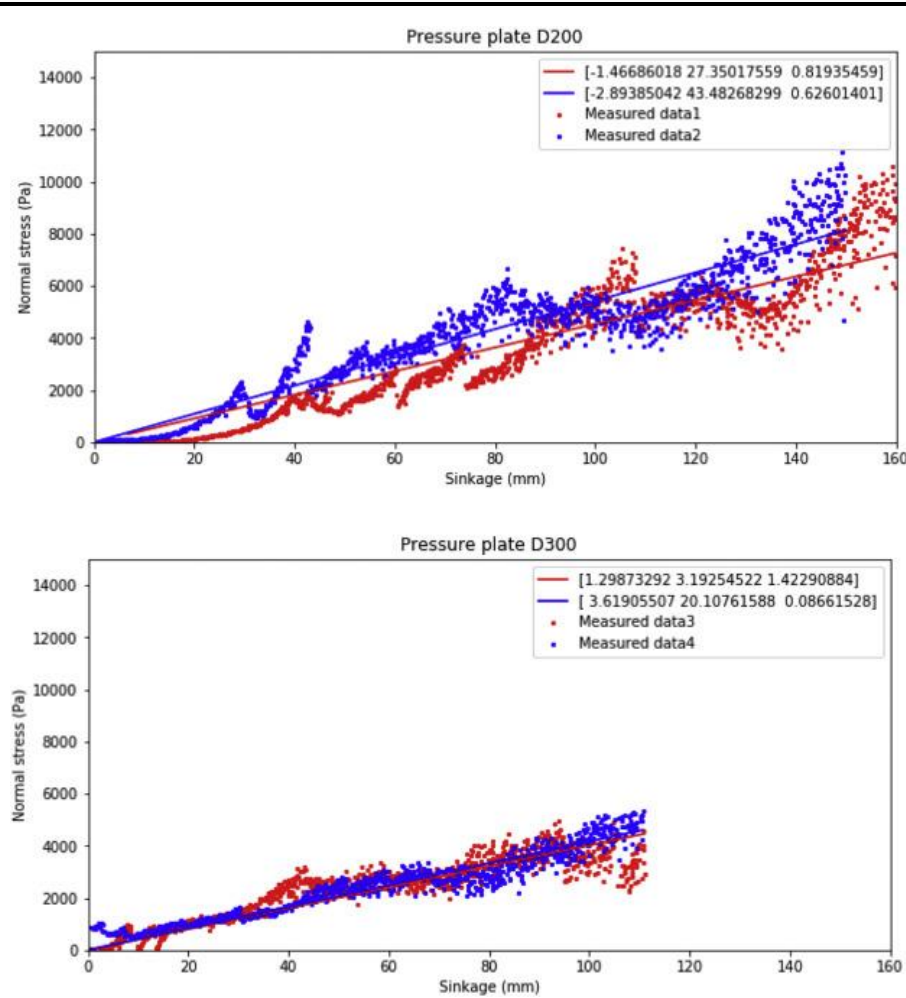

Figure 14. Pressure-sinkage data as well as its fitted curves (Mähönen et al., 2021)
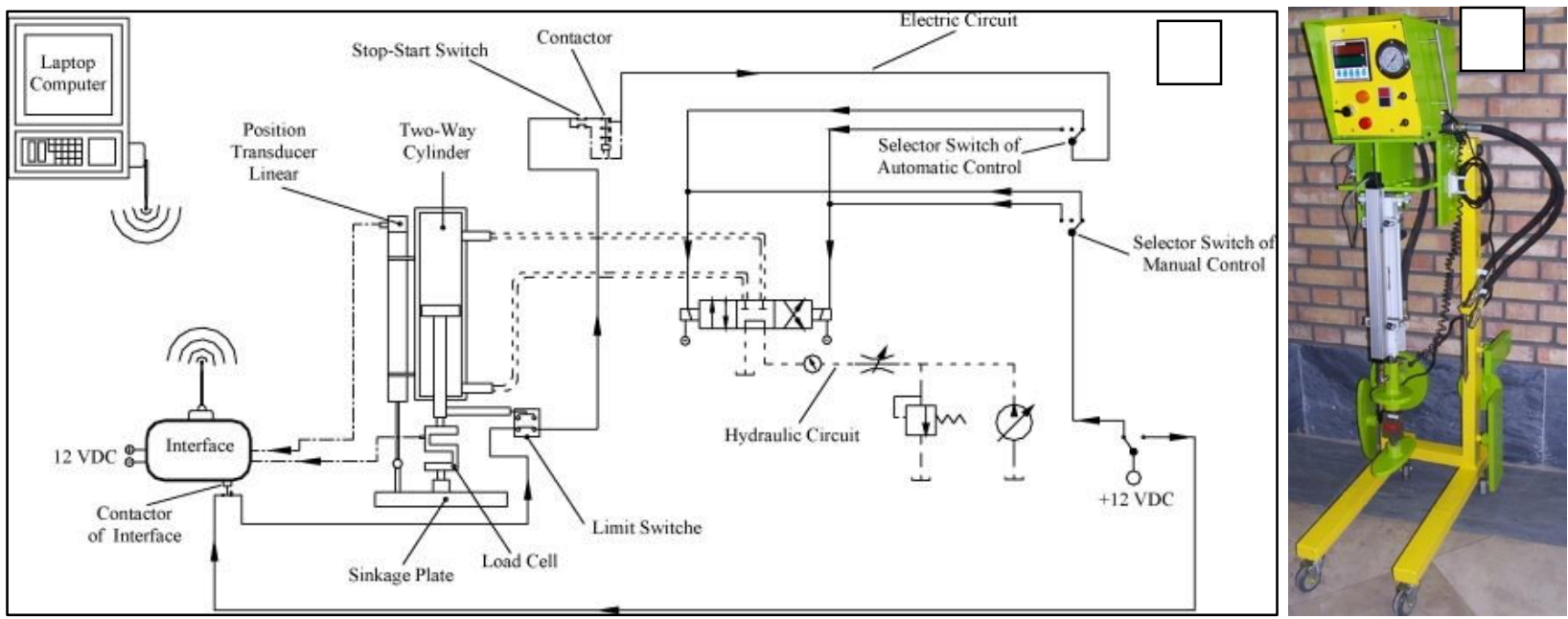

Figure 15. (a) Schematic of bevameter control system, (b) Tractor-mounted bevameter unit on a carrier

(Massah et al., 2010)

Zeleke et al. (2007) determined in situ mechanical characteristics (of two types of forest soils in Ireland) that could be used for their pressure-sinkage properties prediction. The plate sinkage test (Figure 16) was utilized to determine the forest floor mechanical properties. The stiffness values of Young's modulus, the underlying weak peat substrata, and surface mat were determined from the experimental data of an in situ load-sinkage obtained from the sites. They developed a non-linear model by which the pressure-sinkage characteristics were predicted for the forest floor with an error rate of less than $19 \%$. The non-linear model application for the potential site damage prediction by extraction machinery traffic and timber harvesting was exemplified. They observed that such model application has an advantage in which it only requires the soil Young's modulus and the configuration of harvesting machine to be known.

Gotteland et al. (2006) presented a new method for the soil penetration tests modeling by using an experimental device named DECART (shown in Figure 17) as a result of the experimental investigation of 
three standard soils. These soils were chosen to represent the mechanical characteristics of a range of soils: silty sand of cohesive frictional soils, sand for frictional soils, and silt for cohesive soils. The models take into concern the soils' mechanical behavior in which a small vertical sinkage could be assumed comparable to elastic behavior, while the analogy being with plastic behavior in the case of large sinkage. They concluded that the new model permits the pressure-sinkage curves prediction for different plate diameters. It is supposed that this model permits a realistic extrapolation for the bearing surface of a vehicle.

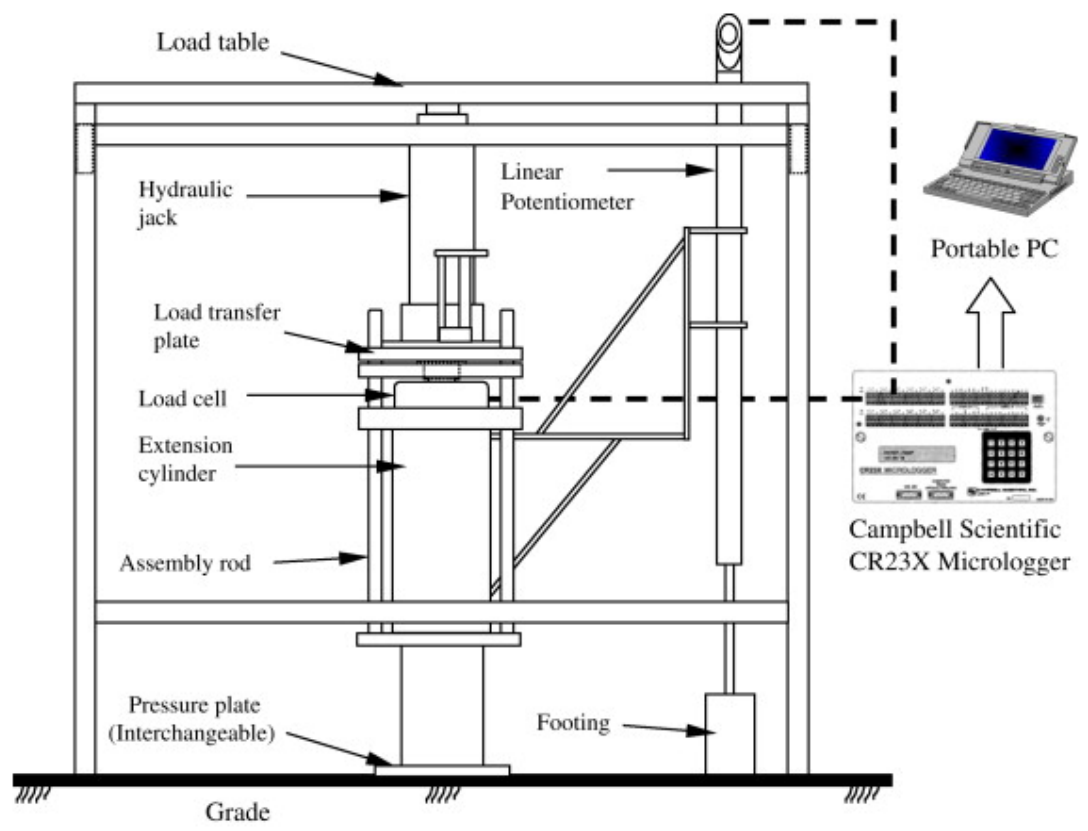

Figure 16. Schematic of the plate-sinkage data acquisition system (Zeleke et al., 2007)

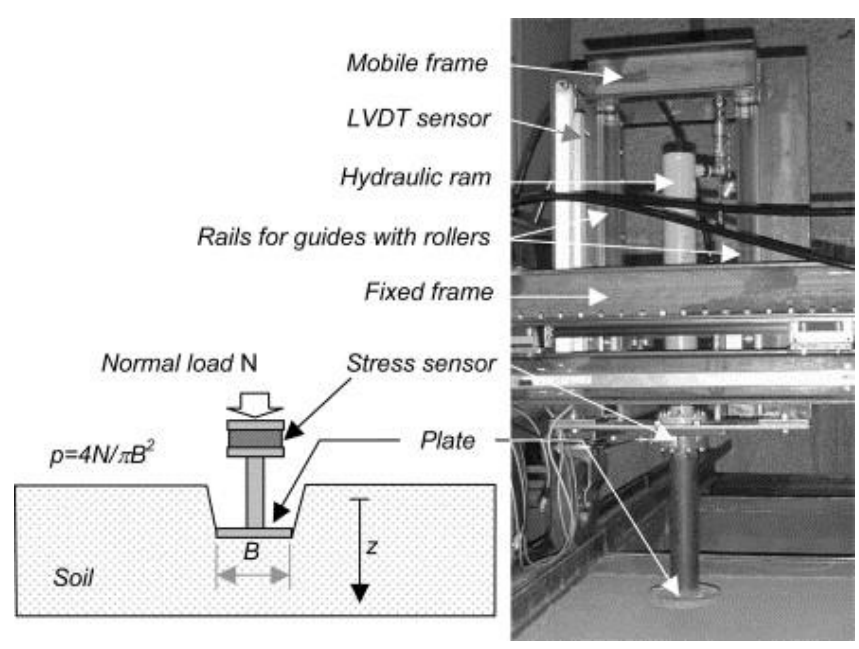

Figure 17. Sinkage-plate equipment (Gotteland et al., 2006)

In order to predict the soil compressibility of the in situ, Mosaddeghi et al. (2006) evaluated two methods confined compression test (CCT) and plate sinkage test (PST). For conducting the in situ CCT and PST, quasi-static loading equipment was designed as shown in Figure 18.

They stated that the PST results can be applied in sustainable soil management in the region concerning trafficability and the influence of different tillage/management systems on soil behavior. The measuring of pre-compaction stress, water content, and cone penetration resistance relationships was recommended for the series of important soil in the region of the test. Also, for practical applications, it was advised to include the soil maps. 


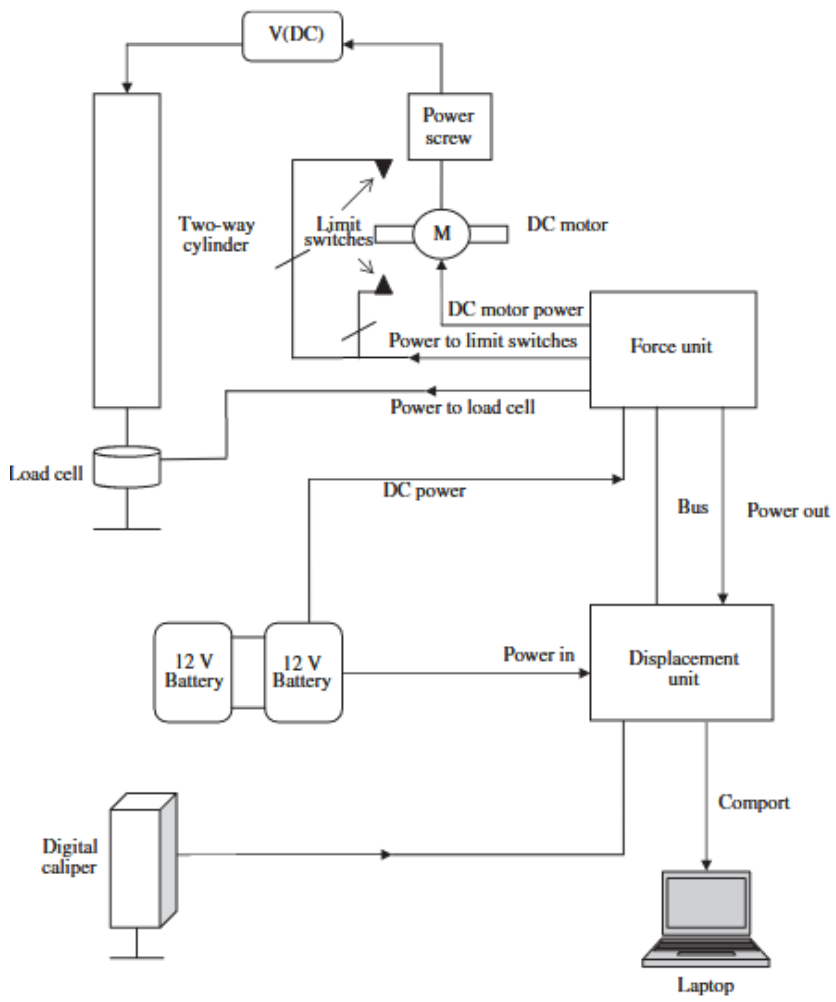

Figure 18. Schematic of an in situ tester of soil compressibility (Mosaddeghi et al., 2006)

To measure soil characteristics relevant to traction, Upadhyaya et al. (1993) developed a fully instrumented apparatus. The equipment could measure soil sinkage parameters (exponent and sinkage constant) employing sinkage plates and soil shear parameters (shear modulus and maximum shear stress) using grouser plates. Furthermore, this device could be utilized for measuring soil cone index. The field tests have been conducted using three various rectangular plates (sinkage tests) and five various rectangular grouser plates (shear tests) in a tilled and a firm Yolo loam soil. The outcomes of these tests confirm that the device serves well in all examined modes.

Alexandrous et al. (1995) proposed a technique that proved its capability of identifying the field soils' precompaction stress in situ with good accuracy utilizing the results of the plate sinkage test. This technique included the use of the plate sinkage equipment of tractor-mounted and thus was somewhat cumbersome for general usage. The results were only valid for specific soils tested and cannot be extrapolated to another condition. Later, the author (Alexandrou et al., 1998) determined the relationship between initial dry bulk density, pre-compaction stress, and volumetric water content was examined by employing the data results of the proposed device.

Golob (1981) developed a bevameter that could perform both shear and pressure-sinkage tests by a single hydraulic cylinder, besides could store digital data instead of analog data.

\section{Conclusion}

As demonstrated by the literature search described in this study, the cone penetrometer has been widely employed in numerous varied implementations. Their popularity could be ascribed to the subsequent reasons: they are easy, quick, and economical, they supply test data that could be analyzed easily, and they are good means for examining sands where the undisturbed sampling is hard. In spite of the popularity of utilizing a cone penetrometer, It is generally admitted that the cone index solely is not sufficient appropriately to define the terrain mechanical properties that are relevant to vehicle mobility.

The bevameter technique seems to be the most proper method for soil strength evaluation. This is mainly due to it does not demand soil parameters interpretation via a model such as proposed for the cone and, maybe more importantly, it represents the technique that most nearly simulates the real situation. Further, it characterizes the parameters of soil directly that cut out errors caused by such interpretation. In addition, the bevameter is the only apparatus that can give a maximum value for the soil shear at the topmost layer that is 
in contact with the vehicle. Moreover, the bevameter provides more information about soil properties that could be employed in the prediction systems, which is based on more analysis. In conclusion, the bevameter and cone penetrometer have remained the most common instruments for soil characterization.

\section{Acknowledgment}

This work was supported by the Stipendium Hungaricum Programme and by the Mechanical Engineering Doctoral School, Szent István Campus, MATE University, Gödöllő, Hungary.

\section{References}

[1] Alexandrou, A., \& Earl, R. (1998). The Relationship among the Pre-compaction Stress, Volumetric Water Content and Initial Dry Bulk Density of Soil. Journal of Agricultural Engineering Research, 71(1), 75-80. https://doi.org/10.1006/jaer.1998.0300

[2] Alexandrous, A., \& Earl, R. (1995). In situe determination of the precompaction stress of a soil. Journal of Agricultural and Engineering Research, (61), 67-72. https://doi.org/10.1006/jaer.1995.1032

[3] ASAE, (1983). ASAE Standard: ASAE S313.1, Soil cone penetrometer. American Society of Agricultural and Biological Engineers, St. Joseph, Michigan

[4] Beckett, C. T. S., Bewsher, S., Guzzomi, A. L., Lehane, B. M., Fourie, A. B., \& Riethmuller, G. (2018). Evaluation of the dynamic cone penetrometer to detect compaction in ripped soils. Soil and Tillage Research, 175, 150-157. https://doi.org/10.1016/j.still.2017.09.009

[5] Bekker, M. G. (1956). Theory of Land Locomotion. University of Michigan Press, Ann Arbor, MI

[6] Chung, S. O., Sudduth, K. A., Motavalli, P. P., \& Kitchen, N. R. (2013). Relating mobile sensor soil strength to penetrometer cone index. Soil and Tillage Research, 129, 9-18. https://doi.org/10.1016/j.still.2012.12.004

[7] de Lima, R. P., da Silva, A. P., Giarola, N. F. B., da Silva, A. R., \& Rolim, M. M. (2017). Changes in soil compaction indicators in response to agricultural field traffic. Biosystems Engineering, 162, 110. https://doi.org/10.1016/j.biosystemseng.2017.07.002

[8] Ding, L., Gao, H., Deng, Z., Li, Y., \& Liu, G. (2014). New perspective on characterizing pressuresinkage relationship of terrains for estimating interaction mechanics. Journal of Terramechanics, 52, 57-76. https://doi.org/10.1016/j.jterra.2014.03.001

[9] Edwards, M. B., Dewoolkar, M. M., Huston, D. R., \& Creager, C. (2017). Bevameter testing on simulant Fillite for planetary rover mobility applications. Journal of Terramechanics, 70, 13-26. https://doi.org/10.1016/j.jterra.2016.10.004

[10] Gao, W., Ren, T., Bengough, A. G., Auneau, L., Watts, C. W., \& Whalley, W. R. (2012). Predicting Penetrometer Resistance from the Compression Characteristic of Soil. Soil Science Society of America Journal, 76(2), 361-369. https://doi.org/10.2136/sssaj2011.0217

[11] Golob, T. B. (1981). Development of a terrain strength measuring system. Journal of Terramechanics, 18(2), 109-118. https://doi.org/10.1016/0022-4898(81)90004-5

[12] Goodin, C., \& Priddy, J. D. (2016). Comparison of SPH simulations and cone index tests for cohesive soils. Journal of Terramechanics, 66, 49-57. https://doi.org/10.1016/j.jterra.2015.09.002

[13] Gotteland, P., \& Benoit, O. (2006). Sinkage tests for mobility study, modelling and experimental validation. Journal of Terramechanics, 43, 451-467. https://doi.org/10.1016/j.jterra.2005.05.003

[14] Hernanz, J. L., Peixoto, H., Cerisola, C., \& Sa, V. (2000). An empirical model to predict soil bulk density profiles in field conditions using penetration resistance, moisture content and soil depth. Journal of Terramechanics, 37, 167-184.

[15] Herrick, J. E., \& Jones, T. L. (2002). A dynamic cone penetrometer for measuring soil penetration resistance. Soil Science Society of America Journal, 66(4), 1320-1324. https://doi.org/10.2136/sssaj2002.1320

[16] Hong, W. T., Yu, J. D., Kim, S. Y., \& Lee, J. S. (2019). Dynamic Cone Penetrometer Incorporated with Time Domain Reflectometry (TDR) Sensors for the Evaluation of Water Contents in Sandy Soils. Sensors, 19(18), 3841. https://doi.org/10.3390/s19183841

[17] Lin, J., Sun, Y., \& Schulze Lammers, P. (2014). Evaluating model-based relationship of cone index, soil water content and bulk density using dual-sensor penetrometer data. Soil and Tillage Research, 138, 9-16. https://doi.org/10.1016/j.still.2013.12.004 
[18] Mähönen, J., Lintzén, N., \& Casselgren, J. (2021). Portable bevameter for measuring snow properties in field. Cold Regions Science and Technology, 182, 103195. https://doi.org/10.1016/j.coldregions.2020.103195

[19] Mason, G. L., Salmon, J. E., McLeod, S., Jayakumar, P., Cole, M. P., \& Smith, W. (2020). An overview of methods to convert cone index to bevameter parameters. Journal of Terramechanics, 87 , 1-9. https://doi.org/10.1016/j.jterra.2019.10.001

[20] Massah, J., \& Noorolahi, S. (2010). Design, development and performance evaluation of a tractormounted bevameter. Soil and Tillage Research, 110(1), 161-166. https://doi.org/10.1016/j.still.2010.07.002

[21] Máthé, L., \& Kiss, P. (2015). Determination of rolling losses of a towed vehicle. Proceedings of the 13th ISTVS European Conference. Rome

[22] Miyamoto, T., Fukami, K., \& Chikushi, J. (2012). Simultaneous measurement of soil water and soil hardness using a modified time domain reflectometry probe and a conventional cone penetrometer. Soil Use and Management, 28(2), 240-248. https://doi.org/10.1111/j.1475-2743.2012.00391.x

[23] Mosaddeghi, M. R., Hemmat, A., Hajabbasi, M. A., Vafaeian, M., \& Alexandrou, A. (2006). Plate Sinkage versus Confined Compression Tests for In Situ Soil Compressibility Studies. Biosystems Engineering, 93(3), 325-334. https://doi.org/10.1016/j.biosystemseng.2005.12.005

[24] Okello, A. (1991). A review of soil strength measurement techniques for prediction of terrain vehicle performance. Journal of Agricultural Engineering Research, 50, 129-155. https://doi.org/10.1016/S0021-8634(05)80010-1

[25] Perumpral, J. V. (1987). Cone Penetrometer Applications - A Review. Transactions of the ASAE, 30(4), 0939-0944. https://doi.org/10.13031/2013.30503

[26] Pillinger, G., Géczy, A., Hudoba, Z., \& Kiss, P. (2018). Determination of soil density by cone index data. Journal of Terramechanics, 77, 69-74. https://doi.org/10.1016/j.jterra.2018.03.003

[27] S. Gorucu, A. Khalilian, Y. J. Han, R. B. Dodd, \& Smith, B. R. (2006). An algorithm to determine the optimum tillage depth from soil penetrometer data in coastal plain soils. Applied Engineering in Agriculture, 22(5), 625-631. https://doi.org/10.13031/2013.21993

[28] Taghavifar, H., \& Mardani, A. (2017). Off-road Vehicle Dynamics. Studies in Systems, Decision and Control. Springer International Publishing, Switzerland, Vol. 70

[29] Upadhyaya, S. K., Wulfsohn, D., \& Mehlschau, J. (1993). An instrumented device to obtain traction related parameters. Journal of Terramechanics, 30(1), 1-20. https://doi.org/10.1016/00224898(93)90027-U

[30] Wong, J. Y. (2010). Terramechanics and Off-Road Vehicle Engineering Second. Elsevier Ltd, Oxford, UK

[31] Zeleke, G., Owende, P. M. O., Kanali, C. L., \& Ward, S. M. (2007). Predicting the pressure--sinkage characteristics of two forest sites in Ireland using in situ soil mechanical properties. Biosystems Engineering, 97(2), 267-281. https://doi.org/10.1016/j.biosystemseng.2007.03.007 